\title{
Correlation between cyberloafing and media consumption: Results of teenagers' self-reports
}

Nadezhda Sivrikova*, South Ural State Humanitarian Pedagogical University: Chelyabinsk, RU Nadezhda Sokolova South Ural State Humanitarian Pedagogical University: Chelyabinsk, RU Natalya Artemeva South Ural State Humanitarian Pedagogical University: Chelyabinsk, RU Svetlana Roslyakova South Ural State Humanitarian Pedagogical University: Chelyabinsk, RU Alexey Savchenkov South Ural State Humanitarian Pedagogical University: Chelyabinsk, RU

\section{Suggested Citation:}

Sivrikova, N., Sokolova, N., Artemeva, N., Roslyakova, S. \& Savchenkov, A. (2021). Correlation between cyberloafing and media consumption: Results of teenagers' selfreports. Global Journal of Information Technology: Emerging Technologies. 11(1), 08-18. https://doi.org/10.18844/giit.v11i1.5743

Received from December 01, 2020; revised from February 11, 2021; accepted from April 26, 2021. Selection and peer review under responsibility of Prof. Dr. Dogan Ibrahim, Near East University, Cyprus.

${ }^{\circ} 2021$ SciencePark Research, Organization \& Counseling. All rights reserved.

\begin{abstract}
The study of the correlation between cyberloafing behaviour and the features of teenage media use became the goal of this research. A total of 121 teenagers (13-15 years old) participated in the survey. There were 61 boys and 60 girls. The results of the study showed that the phenomenon of cyberloafing is not widespread among schoolchildren in Russia. Most often, during lessons, teenagers search the network for the information they need or to communicate. The most popular sources of information for adolescents are the Internet, books and television. The results of the study show that the formation of cyberloafing behaviours is associated with quantitative and qualitative features of adolescent media consumption. The level of cyberloafing depends on media competence, as well as on the characteristics of the perception and processing of media information. The limitations of the presented study are discussed in the final part of this article.
\end{abstract}

Keywords: Cyberloafing, media use, generational psychology, adolescents, teenagers.

\footnotetext{
*ADDRESS FOR CORRESPONDENCE: Nadezhda Sivrikova, Pedagogicheskiy University, Russian Federation.

E-mail address: bobronv@cspu.ru
} 
Sivrikova, N. (2021). Correlation between cyberloafing and media consumption: Results of teenagers' self-reports. Global Journal of Information

\section{Introduction}

Researchers have noted that the introduction of technological innovations and the growth of individual mobile devices have led to the development of educational opportunities through facilitating access to information materials for teachers and students (Saritepeci, 2020). In today's world, information and communication technology have become a natural part of education and learning (Yilmaz, Yilmaz, Ozturk, Sezer \& Karademir, 2015).

The coronavirus pandemic had a huge impact on the introduction of Internet technologies into the educational process. It turned out to be a serious test of sustainability not only for the economy but for the education system too.

Erduran (2020, p. 234) indicated that 'the current health emergency is putting heavy demands on the quality of online learning environments'. For example, in Russia, simultaneously from March 16, 2020, all educational institutions were closed, and from March 23,2020 , the training process throughout the country was organised using distance learning technologies (Kirillova \& Korshunova, 2020). The transition of the educational process to information and communication technologies has caused a number of problems that are actively discussed in society and science (Kirillova \& Korshunova, 2020; Shavykina, 2020; Svishchev \& Kazarian, 2020).

In this work, we turned to the analysis of the risks of distance education caused by the use of information technologies by students during training to solve non-educational problems (cyberloafing).

A review of the scientific literature showed that the problem of cyberloafing from the perspective of psychology is actively discussed in foreign studies. However, in Russia, it is unjustifiably ignored. In addition, in the studies of cyberloafing in the academic environment, attention is concentrated mainly on vocational education. Very few researchers include school graduates in the sample and the prevalence of cyberloafing among secondary school students is practically not investigated. However, the researchers themselves argue that adolescents tend to show deviant behaviour due to age characteristics (Saritepeci, 2020). Other researchers show that the age of children joining mobile communication devices and Internet technologies is decreasing, and their level of competence in using such technologies is growing (Cristia \& Seidl, 2015; Sivrikova et al., 2020). In this regard, researchers urge to focus on the causes of cyberloafing behaviour in the context of education (Ozcan, Gokcearslan \& Okan Yuksel, 2017). Therefore, this work will consider the correlation of cyberloafing behaviour with the features of teenage media use.

\section{Theoretical framework}

\subsection{Cyberloafing}

Cyberloafing is a dynamic phenomenon. The term itself is still discussed and supplemented (Burleson \& Greenbaum, 2019). With regard to the scope of application of this concept, the list of forms of cyberloafing and the phenomenological circle of the phenomenon are expanding.

First, researchers drew attention to the use of workplace Internet by employees in offices visiting non-work-related sites or check personal email (Lim, 2002). In the future, the range of such forms of behaviour will significantly expanded to include the following types of activity in the workplace: the use of social networks, online and offline games, instant messaging, video viewing, downloading games, applications, music and Internet shopping (Durak, 2020; Saritepeci, 2020; Wu, Mei, Liu \& Ugrin, 2020a; Wu, Mei, Ugrin, Liu \& Wang, 2020b). The widespread use of mobile Internet has led to the use of personal mobile devices during working hours to solve personal problems. This has led to another revision of forms of cyberloafing behaviour. Researchers use terms such as traditional cyberloafing, personal cyberloafing and mobile cyberloafing (Batabyal \& Bhal, 2020; Wu et al., 2020a). They suggest using more general categories to describe the phenomenon being studied, for example, 
Sivrikova, N. (2021). Correlation between cyberloafing and media consumption: Results of teenagers' self-reports. Global Journal of Information

'personal use of technology at work' (Burleson \& Greenbaum, 2019; Kim, 2018). The general criteria for assigning behaviour to cyberloafing remain voluntary actions, personal nature of tasks and use of technologies. The essence of behaviour lies in a special form of distraction (care) from solving production (work) tasks using technologies (Koay, 2018a).

Over time, the attitude of researchers to the phenomenon under study has changed. Initially, cyberloafing was considered as a special form of counterproductive behaviour in the workplace (Lim, 2002; O’Neill, Hambley \& Chatellier, 2014b; Ugrin, Pearson \& Nickle, 2018). Recently, the focus of research has shifted to the positive aspects of this behaviour. Researches have shown that cyberloafing behaviour reduces stress, improves mood, promotes self-development, increases motivation and develops the ability to multitask (Andel, Kessler, Pindek, Kleinman \& Spector, 2019; Ozcan et al., 2017; Saleh, Daqqa, AbdulRahim \& Sakallah, 2018; Sivrikova, Roslyakova, Sokolova \& Moiseeva, 2019) In addition, the researchers note that due to the widespread use of cyberloafing, opportunities should be sought for the most effective combination of personal and work tasks (Burleson \& Greenbaum, 2019).

Recently, it has been noted that cyberloafing not only exists in the workplace. Now, cyberloafing is increasingly being studied in the academic environment. For example, Lim (2002, p. 677) defined cyberloafing as 'voluntary act of employees using their companies' Internet access during office hours to surf non-job-related web sites for personal purposes and to check (including receiving and sending) personal email'. With the active introduction of Internet technologies in the educational process, questions are being raised about cyberloafing during training sessions (Durak, 2020; Ozcan et al., 2017). Given the difference between the business and learning environments, it has been proposed to define cyberloafing in the context of learning as 'the learners' tendency to use the Internet during lesson hours for activities that are irrelevant to educational activities' (Ozcan et al., 2017, p. 726) or 'behaviours of use of Internet for the purposes other than course content' (Yilmaz et al., 2015, p. 291).

\subsection{Technology usage status and cyberloafing}

A review of the literature found that the usage status of technology is considered as one of the factors in cyberloafing behaviour (Burleson \& Greenbaum, 2019; Durak, 2019; O'Neill, Hambley \& Bercovich, 2014a; Saritepeci, 2020). The use of technology at work or in the educational environment offers a number of advantages. This is easy access to information, automation of production processes, prostate communication (Durak, 2019) and requires a sufficiently high level of technology ownership. Researches show that increasing frequency and competence in the use of technology leads to an increase in the frequency of cyberloafing in the workplace (Zhang, Akhtar, Zhang \& Sun, 2019) or during training sessions (Baturay \& Toker, 2015; Durak, 2019; Saritepeci, 2020). Moreover, researchers argue that the personal characteristics of millennials (new generation workers) lead to the use of technology at work to solve personal tasks (Kim, 2018). In particular, it is indicated that a special attitude towards the use of technology was formed in people born after the year 2000 . The Internet has instilled in millennials the habit of communicating without taking into account geographical boundaries. They are ready to spend a lot of time communicating online, as this is a significant part of their personal and professional life. At the same time, the border between business and personal communication can be very conditional, and the identity of millennials is associated with their use of technology (Kim, 2018). The learning style used by millennials has its own specifics. Millennials are accustomed to accessing any information around the clock. They prefer an autonomous learning style. They themselves are looking for information, new ideas and solutions on the network and do not like to wait. Of course, this style requires a developed competence in the use of Internet resources and is associated with the risk of distraction to attractive content (Kim, 2018). Despite the fact that the very existence of differences between generations by individual scientists is called into question, this study makes one think about the style of media consumption as a factor in cyberloafing.

We able were not to find in the literature of studies of the correlation of the style of media 
Sivrikova, N. (2021). Correlation between cyberloafing and media consumption: Results of teenagers' self-reports. Global Journal of Information

consumption with the level of cyberloafing. However, recently, the attention of researchers has been 
attracted by the problem of choosing tasks and multitasking as factors in cyberloafing. At the same time, it is believed that the ability to multitask is higher among representatives of those generations who were born in the era of intensive development of Internet technologies (Small \& Vorgan, 2011). A number of researchers have shown that the efficiency of allocating time between solving personal and work problems correlates with regular communication in the network, self-management tactics and conscious socialisation efforts (O'Neill et al., 2014b).

Thus, the results of the studies suggest that the frequency of cyberloafing behaviour correlates with the frequency and level of use of Internet technologies, as well as with the features of the style of media consumption. This hypothesis is partially supported by data obtained from a sample of university students (Tanriverdi \& Karaca, 2018). Currently, there is no data on how similar correlations are characteristic of schoolchildren.

\section{Materials and methods}

\subsection{Procedures and participants}

The research was designed as a correlational research study. The aim of the study was to determine the relationship between the level of cyberloafing and the features of adolescent media use. The study was conducted in 2018 during the summer holidays in summer camp conditions. The study involved schoolchildren aged $13-15$ years (61 boys and 60 girls). The Russian version of the cyberloafing scale was used as research tools (Akbulut et al.) and the questionnaire used was 'individual style of media consumption' (Dolgov et al.).

Question and answer forms were issued to each study participant for self-completion. A few days later, the questionnaires distributed were collected. The survey was anonymous.

\subsection{Instruments}

The scale proposed by Akbulut et al. was used to collect empirical data about the level of adolescents' cyberloafing. The scale was translated into Russian and adapted (Sivrikova et al., 2019). It allows one to evaluate the frequency of manifestations of five types of cyberloafing behaviour during training sessions (Sa - Communication; So - Shopping; Aoc Content; Gg - Gaming; Rtu - Social networks).

The questionnaire 'Individual style of media consumption' was used to determine the features of media consumption of adolescents. It consists of three parts. The first part invites respondents to rank the media (TV, books, radio, Internet, newspapers and magazines) by frequency of use ( 1 = never, $\quad 2$ = rarely, 3 = from time to time, $4=$ often, $5=$ constantly). The second part suggests evaluating the frequency (every day, once every few days or less) and the level of use (novice, intermediate, advanced and expert) of the Internet. The third part of the methodology contains 60 items that need to be evaluated based on the 5-point scale ( 1 $=$ no, 2 = rather no, $3=$ I find it difficult to answer, 4 = rather yes, $5=$ yes). It allows one to define the severity of four elements of the media consumption style: emotional and cognitive involvement in media space (ECI), internal control of media consumption (IC), reflexive criticality of media consumption (RC) and efficiency of information search (EIS).

\subsection{Data analysis}

Spearman's correlation coefficient was used to determine the correlation between the variables under study. Spearman's rank coefficient is used in cases where normality is not provided (Siebert \& Siebert, 2018). Cramer's V test was used for cross-tabulation analysis. Calculations were carried out using IBM Statistical Package for the Social Sciences Statistics 23.0. To build correlation graphs, the Pajek application was used. 


\section{Results}

\subsection{Levels of cyberloafing in adolescents}

The analysis of the frequency of manifestations of various types of cyberloafing in lessons showed that adolescents most often looked for interesting content on the Internet (Table 1).

Table 1. Features of teenagers' cyberloafing behaviour

\begin{tabular}{|c|c|c|c|c|}
\hline Scale & Cyberloafing behaviou & Number & Mean & Std. deviation \\
\hline $\mathrm{Sa}$ & Communication & 121 & 2.7 & 0.89 \\
\hline So & Shoppin & 121 & 1.9 & 0.95 \\
\hline Aoc & $\begin{array}{c}\mathrm{g} \\
\text { Content }\end{array}$ & 121 & 3.1 & 1.14 \\
\hline $\mathrm{Gg}$ & Gaming & 121 & 1.7 & 0.92 \\
\hline Rtu & Social networks & 121 & 2.6 & 1.07 \\
\hline
\end{tabular}

Communication through messengers and social networks was in second place. Teenagers tend to shop and play during lessons the least.

It should be noted that, in general, the level of cyberloafing among adolescents who took part in the study was low. Sample averages did not exceed 3 points. This indicates a rare or extremely rare use of technology in lessons for personal purposes.

\subsection{Features of media consumption of teenagers}

Internet, television and books are most popular among schoolchildren among various media (Table 2).

Table 2. Frequency of use of media by adolescents

\begin{tabular}{lccc}
\hline \multicolumn{1}{c}{ Media } & $\begin{array}{c}\text { Numbe } \\
\mathbf{r}\end{array}$ & Mean & $\begin{array}{c}\text { Std. } \\
\text { deviation }\end{array}$ \\
\hline TV & 121 & 2.5 & 1.23 \\
Internet & 121 & 4.4 & 0.89 \\
Books & 121 & 3.0 & 1.02 \\
Journals & 121 & 1.8 & 0.96 \\
Radio & 121 & 1.9 & 1.16 \\
Newspapers & 121 & 1.6 & 1.15 \\
\hline
\end{tabular}

Traditional forms of press (journals and newspapers) were the least in demand from adolescents.

Radio was not particularly popular with schoolchildren either.

The analysis of the frequency of Internet use showed that the study participants use it every day or several times a day (Table 3).

Table 3. Frequency and level of Internet use by adolescents $(n=121)$

\begin{tabular}{lcccc}
\hline Frequency & Novice & $\begin{array}{c}\text { Level of use } \\
\text { Intermediat } \\
\text { e }\end{array}$ & $\begin{array}{c}\text { Advance } \\
\mathbf{d}\end{array}$ & $\begin{array}{c}\text { Exper } \\
\mathbf{t}\end{array}$ \\
\hline $\begin{array}{l}\text { Once every few } \\
\text { days }\end{array}$ & $16.1 \%$ & $41.9 \%$ & $25.8 \%$ & $16.1 \%$ \\
Every day & & & & \\
Total & $0.0 \%$ & $44.4 \%$ & $41.1 \%$ & $14.4 \%$ \\
\hline
\end{tabular}

$4.1 \%$ of the study participants consider themselves novice to the world of Internet technologies. $43.8 \%$ of the schoolchildren called themselves intermediate users of the network. $37.2 \%$ of the respondents said they were advanced Internet users. $14.9 \%$ considered 
Sivrikova, N. (2021). Correlation between cyberloafing and media consumption: Results of teenagers' self-reports. Global Journal of Information

themselves experts in the field of Internet use. At the same time, it turned out that the frequency of Internet use is associated with assessing the user's own skills ( $V=0.364 ; p=$ $0.001)$. 
Adolescents use the Internet every day or once every few days (Table 3 ). Most of them consider themselves an intermediate $(43.8 \%)$ or advanced $(37.2 \%)$ users of the network.

Analysis of the characteristics of the style of media consumption of adolescents showed that in the participants of the study, the features of media consumption in the order of increasing degree of their expression are arranged as follows: emotional-cognitive involvement, internal control, reflexive criticality and the EIS (Table 4).

A relatively low emotional-cognitive involvement in media space is characteristic of the study participants.

\begin{tabular}{lccc}
\multicolumn{4}{c}{ Table 4. Features of the media consumption style of adolescents } \\
\hline $\begin{array}{l}\text { Elements of media consumption } \\
\text { style }\end{array}$ & $\boldsymbol{N}$ & Mean & $\begin{array}{c}\text { Std. } \\
\text { deviation }\end{array}$ \\
\hline ECl & 121 & 0.9 & 10.28 \\
IC & 121 & 1.4 & 7.28 \\
RC & 121 & 2.7 & 7.25 \\
EIS & 121 & 4.9 & 7.15 \\
\hline
\end{tabular}

Relatively high rates of information retrieval efficiency are a feature of the style of media consumption of adolescents. Adolescents themselves admit that they are well guided in the flow of information on the network or other sources. They can separate truthful information from false information. However, from time to time, study participants have difficulty in solving these problems. Control of own media consumption is not sufficiently developed in study participants. They note that they cannot always control the time spent on media consumption.

\subsection{Correlation between cyberloafing and adolescent media use}

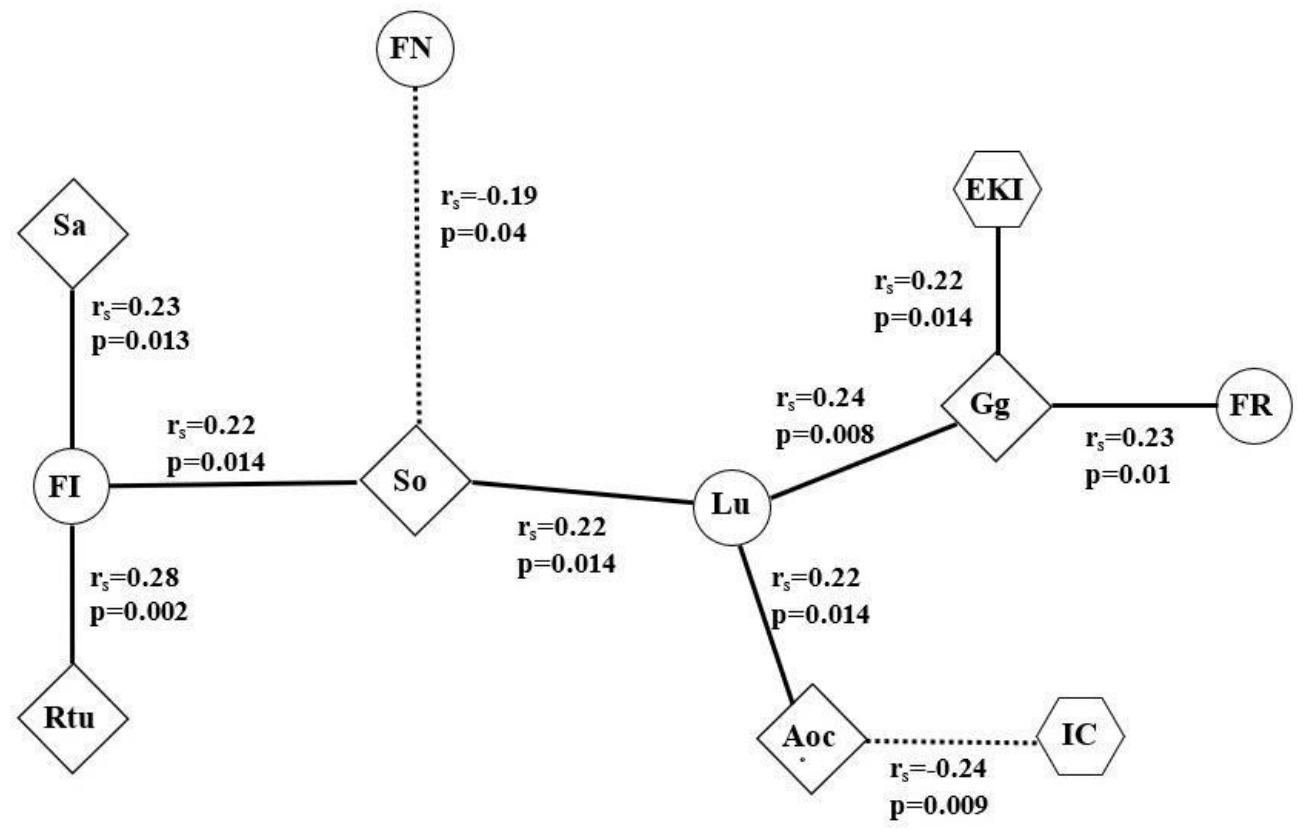

Figure 1.

Correlations between individual types of cyberloafing behaviour and frequency of different media use were found during the study (Figure 1). 
Sivrikova, N. (2021). Correlation between cyberloafing and media consumption: Results of teenagers' self-reports. Global Journal of Information

\begin{tabular}{lll}
\hline Sa - & FI - Frequency of use of the & IC - Internal control of \\
Communication So & Internet LU - Internet user's level & media consumption \\
- Shopping & FN - Frequency of use of the & EKI - Emotional-cognitive \\
Aoc- & newspaper FR - Frequency of use of & involvement in media space \\
Content Gg & the Radio & $r-$ Spearman's Correlation Coefficient \\
- Gaming & & $p-$ significant level (2-tailed) \\
Rtu - Social & &
\end{tabular}

Rtu - Social

networks

It turned out that the frequency of Internet use correlates with the frequency of communication over the Internet and on social networks in lessons. The frequency of reading newspapers correlates with the frequency of visiting online stores during lessons. This correlation is negative. The popularity of radio is associated with the frequency of game behaviour during lessons.

The level of skills of the Internet user correlates with the level of cyberloafing of adolescents too. The frequency of visits to online stores and other sites, as well as game behaviour during lessons in adolescents, increases with the increase in assessments of the user's own skills with the Internet.

The features of the media consumption style correlate with the use of Internet content and games during lessons. Internal control over media consumption turned out to be higher in adolescents, who are less likely to visit sites and download various contents during lessons. As expected, the level of emotional-cognitive involvement in the media space correlates with the frequency of game behaviour during lessons.

\section{Discussion}

The results of the study showed that the phenomenon of cyberloafing affected schoolchildren. Among the participants in the study, it is not yet widespread. It should be noted that according to researchers, a similar picture is noted in Turkey. According to published data, the average level of cyberloafing among high school students is 2.69 points on a 5-point scale (Saritepeci, 2020). Similar results were obtained on samples of students in sixth and seventh grades (Tanriverdi \& Karaca, 2018) and pupils of the universities (Durak, 2020; Koay, 2018b). Access to online content and the exchange of information on social networks can be attributed to the most popular forms of cyber-lapping behaviour among schoolchildren. This result was expected since for adolescence communication is a leading activity. Low rates of shopping as an element of cyberloafing can be explained by the financial dependence of adolescents.

A significant difference between Russian schoolchildren and their foreign peers (Tanriverdi \& Karaca, 2018) and pupils of the universities (Durak, 2020) lies in the rare use of computer and Internet games in lessons. The low frequency of games during lessons may be explained on the one hand by the ban imposed on this species by parents and teachers, and on the other, by the difficulty in concealing this type of cyberloafting.

Kramer (2019) put forward the idea that the feeling of his own freedom in the field of border violation leads to the fact that cyberloafing is not considered as a form of deviant behaviour. As a result, people less dependent on outside control allow themselves to use technology at work to solve their personal (non-work-related) tasks more often than others. People who do not have such freedom (subordinates) feel better following the established rules and prohibitions. In addition, the game requires a great concentration of attention, because of this it is difficult to combine it with solving learning tasks. In this case, it becomes difficult to realise 'polychronicity', as the main reason for cyberloafing (Burleson \& Greenbaum, 2019). The fact that people are engaged in solving personal tasks at work if the work tasks assigned to them are below their competence speaks in favour of this argument (Yilmaz \& Yurdugul, 2018).

Estimates of media use rates such as frequency and computer literacy have proved 
Sivrikova, N. (2021). Correlation between cyberloafing and media consumption: Results of teenagers' self-reports. Global Journal of Information

predictable. Students use the Internet every day or once every few days. This is comparable to data obtained from 
a sample of Turkish students (Koay, 2018b). At the same time, less than $5 \%-20 \%$ of respondents in Russia and Turkey identify themselves as newcomers or experts in the use of information technologies (Koay, 2018b). This suggests a fairly high level of metacognitive awareness of schoolchildren, which is confirmed by the use of other research methods (Saritepeci, 2020). In general, it can be said that the results of the study reflected the tendency for children to increasingly learn information technology, observed by other researchers (Sivrikova et al., 2020). Moreover, we can state that the usual technologies and forms of Internet practices are transferred by schoolchildren to classrooms.

But they are used to solving non-learning tasks.

It is important to note here that the use of information and communication technologies increases the motivation of students, increases the involvement of children in work in the classroom and facilitates understanding and organisation of activities in the classroom according to the results of other studies (Tanriverdi \& Karaca, 2018). However, other studies have shown that adolescents who have access to computers and smart mobile devices in lessons use these devices to solve non-learning problems more often than their peers (Tanriverdi \& Karaca, 2018). This underscores once again that the use of the Internet can become a serious problem for children who lack self-control over time. This is all the more important since the research results confirm that there is a negative correlation between the level of cyberloafing in the workplace and self-control of the personality (Mercado, Giordano \& Dilchert, 2017). And people born after the year 2000 are more prone to boredom and less able to concentrate or pay attention (Kim, 2018).

The results of this study show that adolescents have a satisfactory but not high level of internal control over their own media consumption. In addition, it turned out that the level of IC is negatively correlated with the search and use of Internet content during lessons (the most common type of cyberloafing among adolescents). This makes it possible to give a positive forecast for the introduction of information technologies in the school environment, but subject to control by parents and teachers.

Based on the findings of this study, it was concluded that there is a significant positive relationship between cyberloafing behaviours and features media consumption. The findings showed that the frequency of Internet use and the level of user skills correlated with the frequency of cyberloafing behaviour in the classroom. This has been repeatedly said by cyberloafing researchers in the educational environment (Joseph \& Thomas, 2020; Yilmaz \& Yurdugul, 2018) and at work (Arciniega, Stanley, Puga-Mendez, Obregon-Schael \& PolitiSalame, 2019; Zhang et al., 2019).

During the study, new facts were found such as the level of emotional-cognitive involvement in the media space correlates with the frequency of game behaviour during lessons. This fact confirms that children prone to Internet addiction play computer and Internet games in lessons. Emotional-cognitive involvement is a prerequisite for the formation of such behaviour. The lessons are played by children who are so absorbed in the game that they cannot break away from it, despite the need to solve learning tasks. Such behaviour is a real threat to the educational process.

Thus, the results of the study show that the frequency and level of use of Internet technologies can be considered predictors of cyberloafing behaviours. However, the formation of cyberloafing behaviours correlates with the stylistic features of the perception and processing of media information. The results of the study fill the existing gaps in science and improve understanding of cyberloafing in the academic environment.

\section{Conclusion}

Trends in the digitalisation of society, the intensification of which is associated with the coronavirus pandemic, challenge modern society and education. The rapidly changing nature of work requires a reassessment of the use of information and communication technologies to meet human needs. Radical approaches to assessing the digitalisation of education as an 
Sivrikova, N. (2021). Correlation between cyberloafing and media consumption: Results of teenagers' self-reports. Global Journal of Information

unambiguously positivē or unambiguoüsly negative phenomenon have become biased. The complexity of technology on the one 
Sivrikova, N. (2021). Correlation between cyberloafing and media consumption: Results of teenagers' self-reports. Global Journal of Information

hand and the system of human needs on the other require taking into account numerous nuances. Technology opens up a vast world of knowledge to students and eliminates geographical and temporal barriers. But they carry a lot of risks to health and academic effectiveness. This applies entirely to the problem of cyberloafing.

This study showed that the frequency of cyberloafing is associated with quantitative and qualitative characteristics of media consumption. It has a number of potential limitations that should be taken into account. First, the results are based on adolescent self-reports. Therefore, it is important to continue research on this topic using quantitative and qualitative methods, as well as using the method of collecting objective data. The second limitation is due to the fact that data collection was carried out in an extracurricular environment (in summer camp conditions). It was important that the sharing of Internet access at school, as well as the access of students to school computers during lessons, not be taken into account in the study. At the same time, this factor is decisive in the spread of cyberloafing in school (Saritepeci, 2020).

Analysis of the impact of the transition to distance learning on the spread of cyberloafing in Russian schools is considered as a prospect for further study of the problem.

\section{References}

Andel, S. A., Kessler, S. R., Pindek, S., Kleinman, G. \& Spector, P. E. (2019). Is cyberloafing more complex than we originally thought? Cyberloafing as a coping response to workplace aggression exposure. Computers in Human Behavior, 101, 124-130. doi:10.1016/j.chb.2019.07.013

Arciniega, L. M., Stanley, L. J., Puga-Mendez, D., Obregon-Schael, D. \& Politi-Salame, I. (2019). The relationship between individual work values and unethical decision-making and behavior at work. Journal of Business Ethics, 158(4), 1133-1148. doi:10.1007/s10551-017-3764-3

Batabyal, S. K. \& Bhal, K. T. (2020). Traditional cyberloafing, mobile cyberloafing and personal mobileinternet loafing in business organizations: exploring cognitive ethical logics. Journal of Information, Communication and Ethics in Society, 18. doi:10.1108/JICES-07-2019-0081

Baturay, M. H. \& Toker, S. (2015). An investigation of the impact of demographics on cyberloafing from an educational setting angle. Computers in Human Behavior, 50, 358-366. doi:10.1016/j.chb.2015.03.081

Burleson, J. \& Greenbaum, B. E. (2019). When spheres collide: a refocused research framework for personal use of technology at work. Communications of the Association for Information Systems, 45, 411-432. doi:10.17705/1CAIS.04523

Cristia, A. \& Seidl, A. (2015). Parental reports on touch screen use in early childhood. PLoS One, 10(6), e0128338. doi:10.1371/journal.pone.0128338

Durak, H. Y. (2019). Cyberloafing in learning environments where online social networking sites are used as learning tools: antecedents and consequences. Journal of Educational Computing Research, 58, 539-569. doi:10.1177\%2F0735633119867766

Durak, H. Y. (2020). Cyberloafing in learning environments where online social networking sites are used as learning tools: antecedents and consequences. Journal of Educational Computing Research, 58(3), 539-569. doi:10.1177/0735633119867766

Erduran, S. (2020). Science education in the era of a pandemic. How can history, philosophy and sociology of science contribute to education for understanding and solving the Covid-19 crisis? Science \& Education, 29, 233-235. doi:10.1007/s11191-020-00122-w

Joseph, G. V. \& Thomas, K. A. (2020). Volatility of digital technology enabled learning- Genimon Vadakkemulanjanal. TEST Engineering \& Management, 82, 5832-5839. doi:10.6084/ m9.figshare.11847258.v2

Kim, S. (2018). Managing millennials' personal use of technology at work. Business Horizons, 61(2), 261270. 
Sivrikova, N. (2021). Correlation between cyberloafing and media consumption: Results of teenagers' self-reports. Global Journal of Information

Kirillova, T. V. \& Korshunova, A. A. (2020). Challenges in organizing education using remote education technologies in the context of a pandemic. Pedagogics Questions, (4-2), 180-182. Retrieved from https://www.elibrary.ru/item.asp?id=42781507

Koay, K. Y. (2018a). Workplace ostracism and cyberloafing: a moderated-mediation model. Internet Research, 28(4), 1122-1141. doi:10.1108/IntR-07-2017-0268

Koay, K. Y. (2018b). Assessing cyberloafing behaviour among university students: a validation of the cyberloafing scale. Pertanika Journal of Social Sciences and Humanities, 26(1), 409-424.

Kramer, M. (2019). How much does technology weigh on the work-life balance scale? A qualitative study showing the influence of personal technology usage at the workplace on work-life balance. Mens En Maatschappij, 94(1), 5-28. doi:10.5117/MEM2019.1.002.KRAM

Lim, V. K. G. (2002). The IT way of loafing on the job: cyberloafing, neutralizing and organizational justice. Journal of Organizational Behavior, 23(5), 675-694. doi:10.1002/job.161

Mercado, B. K., Giordano, C. \& Dilchert, S. (2017). A meta-analytic investigation of cyberloafing. Career Development International, 22(5), 546-564. doi:10.1108/CDI-08-2017-0142

O'Neill, T. A., Hambley, L. A. \& Bercovich, A. (2014a). Prediction of cyberslacking when employees are working

away from the office. Computers in Human Behavior, 34, 291-298. doi:10.1016/j.chb.2014.02.015

O'Neill, T. A., Hambley, L. A. \& Chatellier, G. S. (2014b). Cyberslacking, engagement, and personality in distributed work environments. Computers in Human Behavior, 40, 152-160. doi:10.1016/ j.chb.2014.08.005

Ozcan, S., Gokcearslan, S. \& Okan Yuksel, A. (2017). An investigation of the relationship between cyberloafing and academic motivation among university students. Kuresellesen Dunyada Egitim, 52, 733-742. doi:10.14527/9786053188407.52

Saleh, M., Daqqa, I., AbdulRahim, M. B. \& Sakallah, N. (2018). The effect of cyberloafing on employee productivity. International Journal of Advanced and Applied Sciences, 5(4), 87-92. doi:10.21833/ ijaas.2018.04.011

Saritepeci, M. (2020). Predictors of cyberloafing among high school students: unauthorized access to school network, metacognitive awareness and smartphone addiction. Education and Information Technologies, 25(3), 2201-2219. doi:10.1007/s10639-019-10042-0

Shavykina, T. A. (2020). Distance learning in Russia and the United States in a pandemic. In M. M. Matveeva (Ed.), Economics, governance and law in today 's environment (pp. 82-86). Togliatti, Russia: Institute of Forensic Construction and Technical Expertise. Retrieved from https://www.elibrary.ru/ item. asp?id=42856646

Siebert, C. F. \& Siebert, D. C. (2018). Data analysis with small samples and non-normal data: nonparametrics and other strategies. New York, NY: Oxford University Press.

Sivrikova, N., Roslyakova, S., Sokolova, N. \& Moiseeva, E. (2019). Assessing of use of the Internet for personal reasons at lessons at school: a validation of the cyberloafing scale. SHS Web of Conferences, 70, 06010. doi:10.1051/shsconf/20197006010

Sivrikova, N. V., Ptashko, T. G., Perebeynos, A. E., Chernikova, E. G., Gilyazeva, N. V. \& Vasilyeva, V. S. (2020). Parental reports on digital devices use in infancy and early childhood. Education and Information Technologies, 1-17. Retrieved from https://link.springer.com/article/10.1007/s10639020-10145-Z

Small, G. \& Vorgan, G. (2011). Mozg onlain : chelovek v ejpokhu Interneta. St. Petersburg, Russia: Kolibri.

Svishchev, A. V. \& Kazarian, M. (2020). Efficiency of implementation in the educational process of remote education using information systems and technologies. Colloquium-Journal, 10-2(62), 116-118. doi:10.24411/2520-6990-2020-11709

Tanriverdi, O. \& Karaca, F. (2018). Investigating the relationships between adolescents' levels of cognitive absorption and cyberloafing activities according to demographic characteristics. Addicta: The Turkish Journal on Addictions, 5(2). doi:10.15805/addicta.2018.5.2.0052

Ugrin, J. C., Pearson, J. M. \& Nickle, S. M. (2018). An examination of the relationship between culture and cyberloafing using the Hofstede model. Journal of Internet Commerce, 17(1), 46-63. doi:10.1080/15332861.2018.1424395 
Wu, J., Mei, W., Liu, L. \& Ugrin, J. C. (2020a). The bright and dark sides of social cyberloafing: effects on employee mental health in China. Journal of Business Research, 112, 56-64. doi:10.1016/ j.jbusres.2020.02.043

Wu, J., Mei, W., Ugrin, J., Liu, L. \& Wang, F. (2020b). Curvilinear performance effects of social cyberloafing out of class: the mediating role as a recovery experience. Information Technology and People. doi:10.1108/ITP- 03-2019-0105

Yilmaz, R. \& Yurdugul, H. (2018). Cyberloafing in IT classrooms: exploring the role of the psycho-social environment in the classroom, attitude to computers and computing courses, motivation and learning strategies. Journal of Computing in Higher Education, 30(3), 530-552. doi:10.1007/s12528-018-9184-2

Yilmaz, F. G. K., Yilmaz, R., Ozturk, H. T., Sezer, B. \& Karademir, T. (2015). Cyberloafing as a barrier to the successful integration of information and communication technologies into teaching and learning environments. Computers in Human Behavior, 45, 290-298. doi:10.1016/j.chb.2014.12.023

Zhang, J., Akhtar, M. N., Zhang, Y. \& Sun, S. (2019). Are overqualified employees bad apples? A dualpathway model of cyberloafing. Internet Research, 30(1), 289-313. doi:10.1108/INTR-10-20180469 